\title{
Pharmacokinetic/Pharmacodynamic Correlation Analysis of Amantadine for Levodopa-Induced Dyskinesia ${ }^{[\$}$
}

\author{
Elizabeth F. Brigham, Tom H. Johnston, Carl Brown, Jonathon D. S. Holt, Susan H. Fox, \\ Michael P. Hill, Patrick A. Howson, Jonathan M. Brotchie, and Jack T. Nguyen \\ Adamas Pharmaceuticals, Inc., Emeryville, California (E.F.B., C.B., J.D.S.H., J.T.N.); Atuka Inc, Toronto, Ontario, Canada (T.H.J., \\ M.P.H., P.A.H., J.M.B.); Krembil Research Institute, University Health Network, Toronto, Ontario, Canada (T.H.J., S.H.F., J.M.B.); \\ and Morton and Gloria Shulman Movement Disorders Centre and the Edmond J. Safra Program in Parkinson's Disease, Toronto \\ Western Hospital, University Health Network, Division of Neurology, University of Toronto, Toronto, Ontario, Canada (S.H.F.)
}

Received January 3, 2018; accepted June 13, 2018

\begin{abstract}
Dyskinesia is a common motor complication associated with the use of levodopa to treat Parkinson's disease. Numerous animal studies in mice, rats, and nonhuman primates have demonstrated that the $N$-methyl-D-aspartate antagonist, amantadine, dose dependently reduces levodopa-induced dyskinesia (LID). However, none of these studies characterized the amantadine plasma concentrations required for a therapeutic effect. This study evaluates the pharmacokinetic (PK)/pharmacodynamic (PD) relationship between amantadine plasma concentrations and antidyskinetic efficacy across multiple species to define optimal therapeutic dosing. The PK profile of amantadine was determined in mice, rats, and macaques. Efficacy data from the 6-hydroxydopamine rat and the 1-methyl-4-phenyl-1,2,3,6tetrahydropyridine macaque model of LID, along with previously published antidyskinetic efficacy data, were used to establish
\end{abstract}

species-specific PK/PD relationships using a direct-effect maximum possible effect model. Results from the PK/PD model were compared with amantadine plasma concentrations and antidyskinetic effect in a phase 2 study in patients with Parkinson's disease treated with ADS-5102, an extended-release amantadine capsule formulation. Outcomes from each of the species evaluated indicate that the $\mathrm{EC}_{50}$ of amantadine for reducing dyskinesia range from 1025 to $1633 \mathrm{ng} / \mathrm{ml}(1367 \mathrm{ng} / \mathrm{ml}$ for an all-species model). These data are consistent with the mean amantadine plasma concentrations observed in patients with Parkinson's disease ( 1500 ng/ml) treated with ADS-5102 at doses that demonstrated a statistically significant reduction in dyskinesia. These results demonstrate that the $\mathrm{EC}_{50}$ of amantadine for reducing dyskinesia is consistent across multiple species and supports a plasma concentration target of $\sim 1400 \mathrm{ng} / \mathrm{ml}$ to achieve therapeutic efficacy.
This study was supported by funding from Adamas Pharmaceuticals, Inc E.F.B., C.B., J.D.S.H., and J.T.N. are employees of and have received compensation and stock options from Adamas Pharmaceuticals, Inc. T.H.J. has received consultancy payments from and holds an equity stake in Atuka Inc. S.H.F. has received consultancy and research funding from Avanir, Biotie, Britannia, C2N, Cynapsus, Kyowa, Orion, and Zambon; honoraria from the International Parkinson and Movement Disorder Society, CHDI, and American Academy of Neurology; research funding from the Michael J. Fox Foundation for Parkinson's Research, NIH, Parkinson Society Canada, and Toronto Western Foundation; and a salary from the University Health Network Department of Medicine Practice Plan. M.P.H. has received consultancy payments from and holds an equity stake in Atuka Inc. P.A.H has received consultancy from Atuka Inc. J.M.B. has received consultancy payments from Atuka Inc. and Adamas Pharmaceuticals, Inc.; and holds an equity stake in Atuka Inc. No other potential conflicts of interest relevant to this article are reported.

Part of this work was presented as follows: Brigham EF, Johnston TH, Brown C, Holt JDS, Fox SH, Hill MP, Howson PA, Brotchie JM, and Nguyen JT. PK-PD analysis identifies similar high amantadine plasma concentrations needed to reduce L-DOPA induced dyskinesia across multiple species. Neuroscience 2017: The Society for Neuroscience Annual Meeting; 11-15 November 2017; Washington, DC. The Society for Neuroscience, Washington, DC.

https://doi.org/10.1124/jpet.118.247650.

S This article has supplemental material available at jpet.aspetjournals.org.

\section{Introduction}

Dopamine replacement therapy with the dopamine precursor, L-3,4-dihydroxyphenylalanine (levodopa), remains the most effective symptomatic treatment of Parkinson's disease. However, long-term treatment with levodopa often leads to the development of motor complications including dyskinesia, which is characterized by involuntary movements that are nonrhythmic, purposeless, and may be unpredictable in onset and severity. In patients treated with levodopa, dyskinesia can develop early, affects nearly $90 \%$ of such patients within approximately 10 years of treatment (Ahlskog and Muenter, 2001), and has a substantial adverse effect on quality of life (Suh et al., 2012).

Although the progressive loss of dopaminergic neurons is the hallmark of Parkinson's disease, the dysregulation of glutamatergic signaling pathways is a major contributor to the development and expression of dyskinesia (Sgambato-Faure and Cenci, 2012). Adaptations to fluctuating levels of dopamine and loss of dopamine modulation have been associated with

ABBREVIATIONS: AE, adverse event; AIM, abnormal involuntary movement; ALO, axial, limb, and orolingual; AUC $_{\text {inf, }}$ area under plasma concentration-time curve at infinity; $\mathrm{Cl}$, confidence interval; $C_{\max }$, maximal plasma concentration; $\mathrm{CNS}$, central nervous system; $\mathrm{CRL}$, Charles River Laboratories; $\mathrm{EC}_{50}, 50 \%$ effective plasma concentration; $\mathrm{E}_{\max }$, maximum possible effect; $\mathrm{IC}_{50}, 50 \%$ inhibitory drug concentration; IR, immediaterelease; LID, levodopa-induced dyskinesia; MPTP, 1-methyl-4-phenyl-1,2,3,6-tetrahydropyridine; NHP, nonhuman primate; NMDA, N-methyl-Daspartate; 6-OHDA, 6-hydroxydopamine; PD, pharmacodynamics; PK, pharmacokinetics; UDysRS, Unified Dyskinesia Rating Scale. 
increased concentrations of extracellular glutamate in animal models (Jonkers et al., 2002; Robelet et al., 2004; Dupre et al., 2011), and increased expression and/or increased activity of the $N$-methyl-D-aspartate (NMDA)-type glutamate receptor in animal models and humans (Calon et al., 2002). The role of glutamate dysregulation in the development and expression of dyskinesia is supported by the antidyskinetic activity of diverse NMDA receptor antagonists in animal models of Parkinson's disease and in humans. For example, a competitive NMDA receptor antagonist [(3S,4aR,6S,8aR)-6-(phosphonomethyl)1,2,3,4,4a,5,6,7,8,8a-decahydroisoquinoline-3-carboxylic acid (LY235959)] significantly decreased dyskinesia in 1-methyl-4phenyl-1,2,3,6-tetrahydropyridine (MPTP)-lesioned parkinsonian nonhuman primates (NHPs) treated with levodopa (Papa and Chase, 1996). Treatment with the high-affinity, uncompetitive NMDA receptor antagonist MK-801 (dizocilpine) in rodent and NHP models of levodopa-induced dyskinesia (LID) resulted in reduced dyskinesia (Bibbiani et al., 2005), and treatment with dextromethorphan, which is also an uncompetitive NMDA receptor antagonist, reduced dyskinesia in humans with Parkinson's disease (Verhagen Metman et al., 1998a).

Amantadine is a low-affinity, uncompetitive NMDA receptor antagonist (Parsons et al., 1995). Numerous studies in mice, rats, and NHPs have demonstrated that amantadine reduces dyskinesia in models of LID in a dose-dependent manner. In mouse and rat, effective doses of amantadine ranged from 10 to $60 \mathrm{mg} / \mathrm{kg}$ (subcutaneous or intraperitoneal administration) in the 6-hydroxydopamine (6-OHDA) model. Amantadine had a consistent benefit at a doses $\geq 40 \mathrm{mg} / \mathrm{kg}$, whereas lower doses had variable effects (Dekundy et al., 2007; Bido et al., 2011; Kobylecki et al., 2011; Paquette et al., 2012; Papathanou et al., 2014; Bortolanza et al., 2016; Sebastianutto et al., 2016). In NHPs (cynomolgus macaques and marmosets) that were administered MPTP to induce parkinsonian disability, chronic treatment with levodopa produces dyskinesia similar to that in humans. Acute treatment (oral or subcutaneous) with amantadine at $0.3-30 \mathrm{mg} / \mathrm{kg}$ resulted in a significant reduction of dyskinesia (Blanchet et al., 1998; Hill et al., 2004; Bibbiani et al., 2005; Kobylecki et al., 2011; Bezard et al., 2013; Grégoire et al., 2013; Ko et al., 2014). Results from multiple small clinical studies indicate an immediate-release (IR) form of amantadine provides antidyskinetic benefits in patients with Parkinson's disease, with efficacy increasing at higher plasma concentrations (Verhagen Metman et al., 1998b).

Despite a half-life of approximately 17 hours, the total daily dose of amantadine IR is typically split to two or three times daily administration due to dose-limiting central nervous system (CNS) adverse events (AEs) associated with oncedaily dosing (Parkes et al., 1970; Hayden et al., 1983). Higher doses that may produce a greater antidyskinetic effect are associated with an increased frequency of CNS AEs, such as dizziness, hallucinations, and sleep disturbances (Parkes et al., 1970). The ADS-5102 (amantadine) extended-release capsule (GOCOVRI; Adamas Pharmaceuticals, Inc., Emeryville, CA) is the first and only US Food and Drug Administration-approved medicine for the treatment of dyskinesia in patients with Parkinson's disease receiving levodopa-based therapy, with or without concomitant dopaminergic medications. The recommended dose of ADS-5102 for the treatment of dyskinesia is $274 \mathrm{mg}$ once daily at bedtime (equivalent to a daily 340-mg dose of amantadine $\mathrm{HCl}$ ). Bedtime administration of ADS-5102 provides high amantadine plasma concentrations in the morning, which are sustained throughout the day when dyskinesias occur (Hauser RA, Pahwa R, Wargin W, et al., manuscript in preparation). Multiple randomized, placebo-controlled trials demonstrated that ADS-5102 significantly reduced dyskinesia in patients with Parkinson's disease who were treated with levodopa, with a secondary benefit of reduced OFF-time associated with motor complications (Pahwa et al., 2015, 2017; Oertel et al., 2017).

To date, none of the reported animal studies included a determination of amantadine plasma concentrations required to obtain a therapeutic effect. The objective of the current analysis was to determine the amantadine plasma concentrations required to reduce dyskinesia in multiple species and any correlations across species. The pharmacokinetic (PK) profile of amantadine was determined in mice, rats, and cynomolgus macaques, and the efficacy of amantadine in reducing LID was assessed in Parkinson's disease models (6OHDA-rat and MPTP-macaque). The PK data were used to build species-specific PK models that were applied to new efficacy data reported herein and previously published efficacy data in mice, rats, and macaques. A PK/pharmacodynamics (PD) relationship was established to determine the $\mathrm{EC}_{50}$ values of amantadine required for the reduction of dyskinesia in these LID animal models. In a recent clinical study, amantadine plasma concentrations associated with the antidyskinetic efficacy of ADS-5102 were reported in patients with Parkinson's disease (Pahwa et al., 2015); these concentrations were compared with the results of the model. These results provide the rationale for target therapeutic plasma amantadine concentrations, with the goal of maximizing antidyskinetic efficacy, in patients with Parkinson's disease treated with levodopa as well as supporting the validity of these animal models for testing novel antidyskinetic drugs.

\section{Materials and Methods}

The PK time course of amantadine plasma levels was determined in mice (eight per group), rats (six per group), and macaques (eight per group), and efficacy was evaluated in rat and macaque models of Parkinson's disease with established LID $(n=6$ /group for rats and $n=$ 8/group for macaques). All studies were performed with local Institutional Animal Care and Use Committee approval as well as in accordance with the Guide for the Care and Use of Laboratory Animals (1996) as adopted by the National Institutes of Health Committee on Care and Use of Laboratory Animals. The mouse PK study was conducted at Charles River Laboratories (CRL; Wilmington, MA) in normal C57BL/6J mice (The Jackson Laboratory, Sacramento, CA), the rat PK study was conducted at CRL in normal Sprague-Dawley rats (CRL, Raleigh, NC), and the NHP PK and LID efficacy study was conducted at Atuka (Suzhou, People's Republic of China) in levodopatreated MPTP macaques (Macaca fascicularis; Suzhou Xishan Zhongke Laboratory Animal Company, Suzhou City, People's Republic of China).

Blood samples $(0.1-0.15 \mathrm{ml})$ were collected at the time points specified for each species below, and the collected plasma was frozen $\left(-70^{\circ}\right.$ to $\left.-80^{\circ} \mathrm{C}\right)$ and stored until processed and analyzed by liquid chromatography-tandem mass spectrometry, as described in the bioanalysis section of the Supplemental Material. A rat LID efficacy study was conducted at Atuka (Toronto, ON, Canada) in levodopatreated 6-OHDA-lesioned Sprague-Dawley rats (CRL, Senneville, QC, Canada). Plasma concentrations were reported in this experiment. Additional PD data were included from a selection of publications that 
reported antidyskinetic efficacy in mouse, rat, or cynomolgus macaque to support the PK/PD model. In addition, amantadine plasma concentrations and antidyskinetic efficacy data from a phase 2 study in Parkinson's disease patients treated with ADS-5102, an extendedrelease amantadine capsule formulation (Pahwa et al., 2015), were compared with the model. Greater detail for all rodent, macaque, and human studies is provided in the Supplemental Material.

PK Studies and PK Modeling. Normal male and female C57BL/6J mice were administered a single dose of 10,30 , or $60 \mathrm{mg} / \mathrm{kg}$, i.p., amantadine $\mathrm{HCl}$ (MOEHS Catalana SL, Barcelona, Spain), and sparse blood samples were collected from the submandibular vein at $0.25,0.5,1,2,4,6,8$, and 12 hours after dosing. Each mouse contributed two samples to the analysis, and each time point represented samples from four animals per sex.

Normal male and female Sprague-Dawley rats were administered a single dose of 15,45 , or $90 \mathrm{mg} / \mathrm{kg}$, i.p., amantadine $\mathrm{HCl}$ (Sigma-Aldrich, St. Louis, MO), and blood samples were obtained via jugular vein cannula at predose, $0.25,0.5,1,2,4,6,8,12$, and 24 hours after dosing. Plasma also was collected in levodopa-treated 6-OHDA-lesioned rats infused subcutaneously continuously for 12 days with amantadine via ALZET (Cupertino, CA) pump (see below).

Four oral doses of amantadine $(1,3,10$, and $30 \mathrm{mg} / \mathrm{kg})$ were given to each of eight MPTP-lesioned macaques in an ascending, nonrandomized treatment design after an overnight fast. Blood samples were collected from the saphenous vein predose, and at $0.25,0.5,1,2,4,6,8$, $12,24,36$, and 48 hours postdose. A 1-week washout occurred between each treatment.

Time-course PK data for each species were fit to an appropriate model and curve using Phoenix WinNonlin version 6.3 (Build 6.3.0.395; Certara, Princeton, NJ). For each species, the critical constants for the exposure-time curve for each dose level were averaged to produce a dose-independent exposure-time curve that could be used to simulate exposure-time curves for dose levels used in the literature for which no experimentally determined PK data were available.

Behavioral Assessment of Effects of Amantadine on Dyskinesia and Abnormal Involuntary Movements: Overview. Results from a 6-OHDA rat study and an MPTP macaque study described below along with the previously published studies identified in Supplemental Table 1 were used as the data source for the effect of amantadine on NHP dyskinesia or the rodent correlate [abnormal involuntary movements (AIMs)]. Published mouse and rat studies in which amantadine was administered intraperitoneally and reported a time course of reduction of AIMs after levodopa treatment, and published NHP studies in which macaques received oral amantadine were included in the analyses. Variations in the key study design components are also presented in Supplemental Table 1.

Continuous Amantadine Administration in 6-OHDA-Lesioned Rats. Female Sprague-Dawley rats (six per group) received unilateral nigrostriatal dopaminergic lesions of the median forebrain bundle using standard stereotaxic techniques (Paxinos and Watson, 1986). Only animals demonstrating a $\geq 85 \%$ asymmetry score in the forelimb asymmetry cylinder test were included in the study. These animals were treated with $10 \mathrm{mg} / \mathrm{kg}$ levodopa methyl ester $\mathrm{HCl}$ in combination with $15 \mathrm{mg} / \mathrm{kg}$, i.p., benserazide $\mathrm{HCl}$ once daily in a dose volume of $1 \mathrm{ml} / \mathrm{kg}$ for 58 days to induce stable AIMs.

Three subtypes of AIMs [axial, limb, and orolingual (ALO)] were assessed (Supplemental Material). Animals were observed for 1 minute before levodopa treatment and 1 minute every 20 minutes for 3 hours after levodopa treatment. Animals obtaining a score of 3 (marked) or 4 (severe) for AIMs during at least one assessment point were included in the study. Animals were assigned to treatment groups so that the baseline AIM scores (via blinded assessment) were not different between each group. ALZET osmotic pumps (model 2ML2; $5 \mu \mathrm{l} / \mathrm{h}, 14$-day pump) containing either vehicle ( $25 \mathrm{mM}$ sodium acetate buffer, $\mathrm{pH} 5.0$ ) or amantadine $\mathrm{HCl}$ delivering $22.5,45$, or $83 \mathrm{mg} / \mathrm{kg}$ per day, s.c., were used. During the amantadine treatment period, all animals received once-daily levodopa $(10 \mathrm{mg} / \mathrm{kg}$ levodopa $/ 15 \mathrm{mg} / \mathrm{kg}$ benserazide, i.p.), and the effects of treatments on AIMs were assessed on treatment day 12 , as described in the Supplemental Material. Cumulative AIMs (20-120 minutes) resulting from the levodopa challenge on amantadine treatment day 12 were compared with cumulative AIMs scored at baseline, before pump implantation.

Referenced AIMs Data from Published Rodent Studies. In addition to the de novo efficacy data generated and reported herein, efficacy data from mouse and rats studies were collected from literature reports (Bido et al., 2011; Papathanou et al., 2014; Bortolanza et al., 2016; Sebastianutto et al., 2016), in which amantadine was administered as a single intraperitoneal dose; ALO AIMs in these reported studies were assessed as described in the Supplemental Material and Supplemental Table 1. Where not explicitly provided, data on AIMs were extracted using WebPlotDigitizer (version 3.6).

Oral Administration of Amantadine in MPTP Macaques. For the NHP, both the de novo efficacy data reported here as well as data obtained from literature reports were used to build the PK/PD model (Bezard et al., 2013; Grégoire et al., 2013; Ko et al., 2014). For our study, the development of the MPTP-macaque LID model is described in the Supplemental Material.

For efficacy assessments, in an acute challenge randomized design, each of eight macaques was administered (via oral gavage) vehicle (water) or four doses of amantadine $(1,3,10$, or $30 \mathrm{mg} / \mathrm{kg}$ ) after an overnight fast. Amantadine or vehicle was administered 1 hour before levodopa, and dyskinesia was assessed over a 6 -hour period of observation (Supplemental Material). A 72-hour washout period occurred between treatments. Data derived from the assessment of NHP measures of dyskinesia were graphed as median scores (time course).

For the efficacy data from the literature (Bezard et al., 2013; Grégoire et al., 2013; Ko et al., 2014) included in the NHP PK/PD analysis, the severity of dyskinesia was rated using dyskinesia scales described in the original publication and summarized in Supplemental Table 1. Where not explicitly provided, dyskinesia data were extracted using WebPlotDigitizer (version 3.6).

PK/PD Analysis. A similar methodology was used for all species. Simulated PK exposure-time curves were used to provide plasma levels of amantadine at the time points after amantadine treatment that correlated with the AIM or dyskinesia observation time points described below. Peak dyskinesia or AIMs generally occur beginning approximately 20 minutes after the administration of levodopa and are sustained through 120 minutes after levodopa administration. Amantadine plasma concentrations were used to assess the exposureresponse relationship for the reduction of dyskinesia at time points in which moderate dyskinesia was measured in the vehicle group (Supplemental Fig. 1). Values less than zero were assigned a value of zero. For the PK/PD relationship, a sigmoidal maximum possible effect $\left(\mathrm{E}_{\text {max }}\right.$ ) model using Prism version 3.6 (GraphPad Software, La Jolla, CA) was fit to the data assuming an $\mathrm{E}_{\max }$ of $100 \%$. Details of doses and time points from previously published rodent and macaque studies are provided in Supplemental Material and Supplemental Table 1.

\section{Results}

Amantadine PK/PD Analysis in Mice. The mean amantadine plasma concentration-time profiles after the administration of a single dose of amantadine $(10,30$, or $60 \mathrm{mg} / \mathrm{kg}$, i.p.) in mice are displayed in Fig. 1A. Amantadine exposures increased proportionally with dose over this range, with mean $C_{\max }$ values ranging from 1268 to $8826 \mathrm{ng} / \mathrm{ml}$ and mean area under plasma concentration-time curve at infinity $\left(\mathrm{AUC}_{\mathrm{inf}}\right)$ ranging from 1781 to $13,877 \mathrm{ng} / \mathrm{h}$ per milliliter (Table 1 ). The composite profile of each dose was modeled using a onecompartment model with an intravenous bolus to optimize the 
A

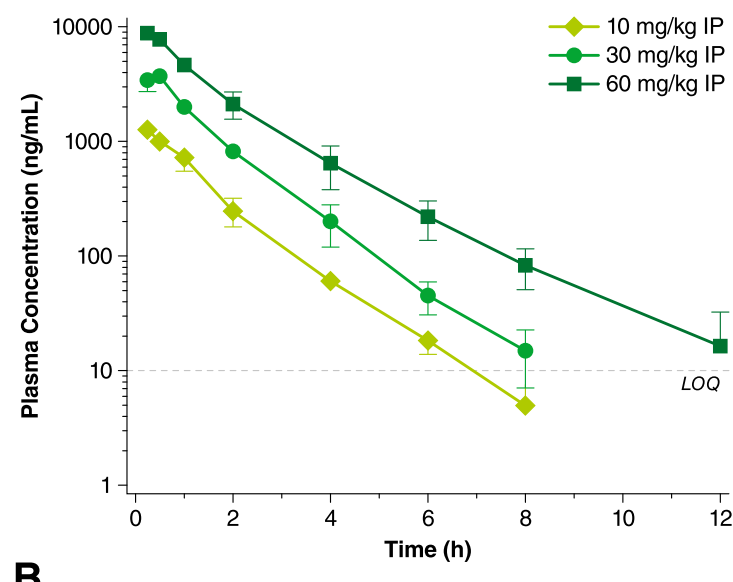

B

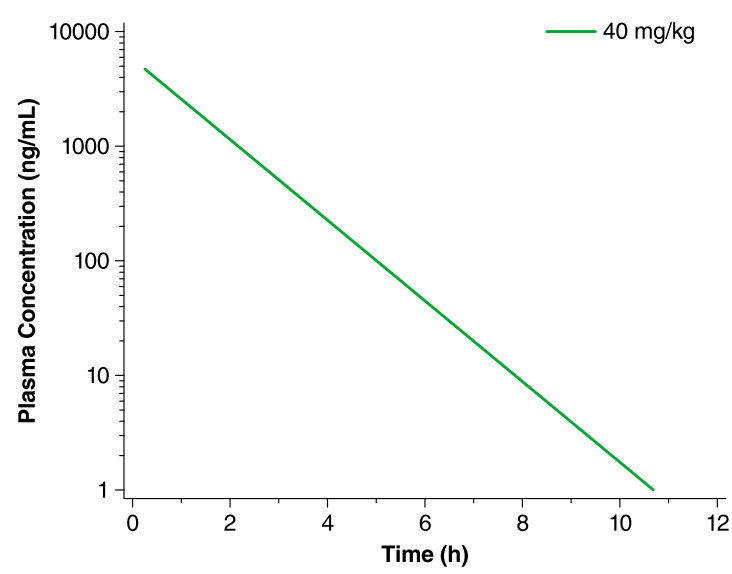

C

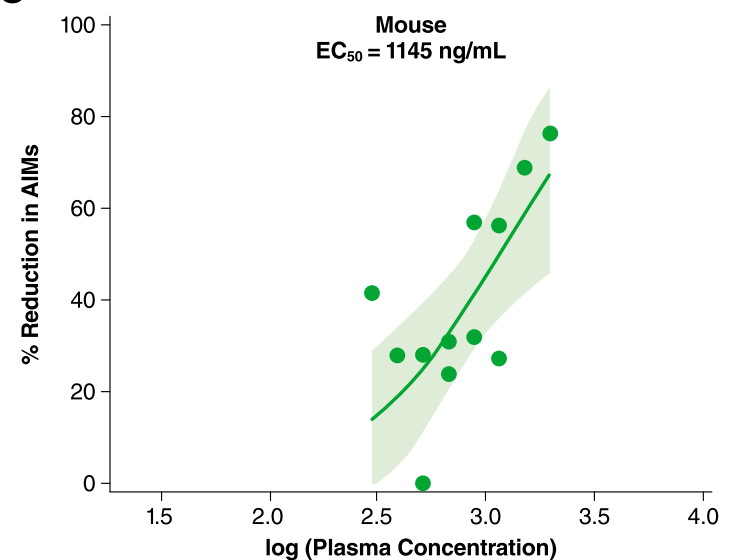

D

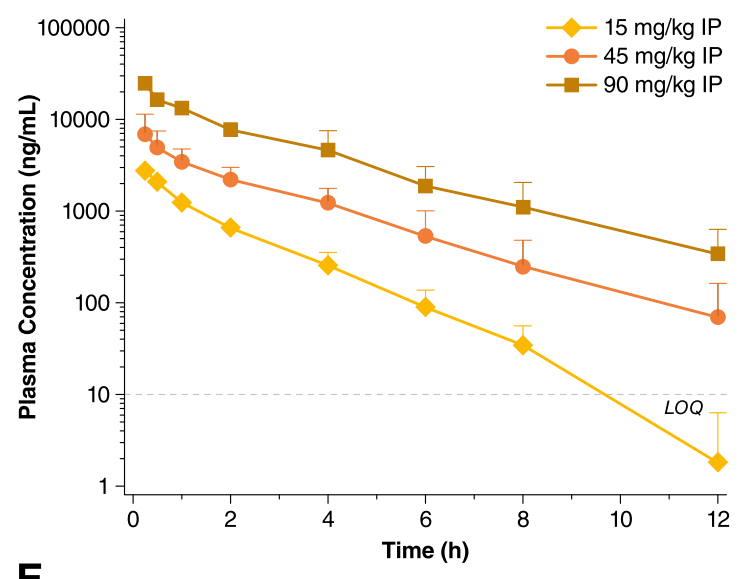

$\mathbf{E}$

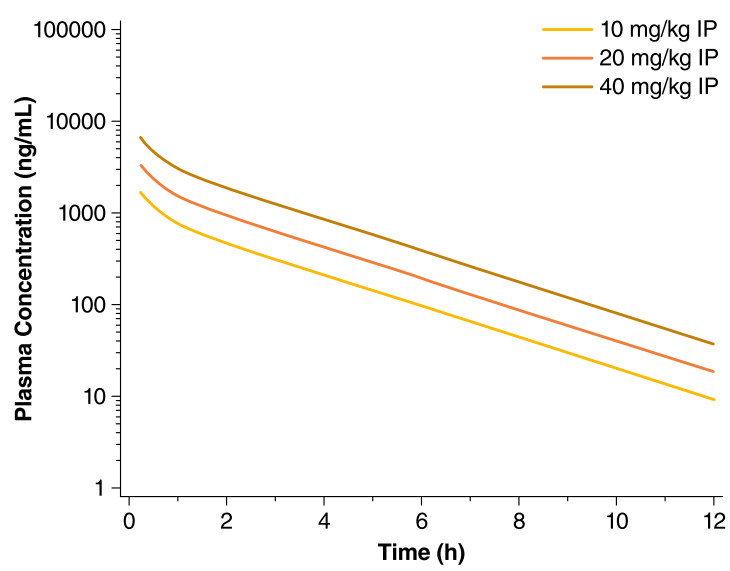

$\mathbf{F}$

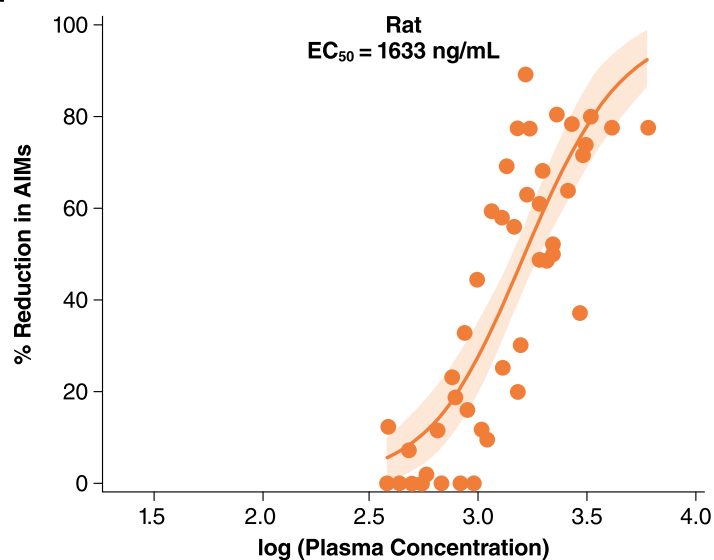

Fig. 1. Amantadine plasma concentration-time profiles after a single intraperitoneal injection dose in mice for observed plasma concentrations (mean \pm S.D.) (A) and simulated plasma concentrations (the PK model) (B). (C) Determination of the PK/PD relationship and the EC $\mathrm{E}_{50}$ in mouse. The percentage reduction from vehicle in AIMs is plotted as a function of the $\log$ (amantadine plasma concentration) in mouse. $\mathrm{EC}_{50}=1145 \mathrm{ng} / \mathrm{ml}$. The shaded area represents 95\% CI. Amantadine plasma concentration-time profiles after a single intraperitoneal injection dose in rat for observed plasma concentrations (mean \pm S.D.) (D) and simulated plasma concentrations (the PK model) (E). The simulated model was fit optimized to maximum plasma concentration, two-compartment intravenous bolus model. (F) Determination of the PK/PD relationship and the $\mathrm{EC}_{50}$ value in rat. The percentage reduction from vehicle in AIMs is plotted as a function of the $\log$ (amantadine plasma concentration) in rat. $\mathrm{EC}_{50}=1633 \mathrm{ng} / \mathrm{ml}$. The shaded area represents the $95 \%$ CI.

fit to $C_{\max }$, and the average parameters (Table 1 ) were used to simulate a $40 \mathrm{mg} / \mathrm{kg}$ dose (Fig. 1B). Bido et al. (2011) and Sebastianutto et al. (2016) demonstrated that $40 \mathrm{mg} / \mathrm{kg}$, i.p., amantadine decreased AIMs as a function of time after a levodopa challenge, achieving maximum reductions of $76 \%$ and $42 \%$, respectively, compared with vehicle.
The percentage of reduction in AIMs was plotted as a function of simulated amantadine plasma concentrations (Fig. 1C). A sigmoidal $\mathrm{E}_{\max }$ model provided a good fit for the data with an amantadine $\mathrm{EC}_{50}$ of $1145 \mathrm{ng} / \mathrm{ml}(95 \%$ confidence interval [CI], $756-1735 \mathrm{ng} / \mathrm{ml}$ ) for the reduction of AIMs (Supplemental Table 2). 
TABLE 1

Amantadine PK parameters by species

\begin{tabular}{|c|c|c|c|c|c|}
\hline & $\begin{array}{l}\text { Mouse, Sexes Combined } \\
10 \mathrm{mg} / \mathrm{kg}\end{array}$ & $30 \mathrm{mg} / \mathrm{kg}$ & $60 \mathrm{mg} / \mathrm{kg}$ & & Mean $^{a}$ \\
\hline \multicolumn{6}{|l|}{ NCA parameter } \\
\hline$C_{\max }(\mathrm{ng} / \mathrm{ml})$ & 1268 & 3733 & 8826 & & \\
\hline$C_{\max } /$ dose $(\mathrm{ng} / \mathrm{ml}) /(\mathrm{mg} / \mathrm{kg})$ & 127 & 124 & 147 & & \\
\hline $\mathrm{T}_{\max }(\mathrm{h})$ & 0.25 & 0.5 & 0.25 & & \\
\hline $\mathrm{AUC}_{\text {inf }}(\mathrm{ng} / \mathrm{h}$ per milliliter $)$ & 1781 & 5522 & 13,877 & & \\
\hline $\mathrm{AUC}_{\text {inf }} / \mathrm{dose}(\mathrm{ng} / \mathrm{h}$ per milliliter $) /(\mathrm{mg} / \mathrm{kg})$ & 178 & 184 & 231 & & \\
\hline$t_{1 / 2}(\mathrm{~h})$ & 1.1 & 1.0 & 1.5 & & \\
\hline \multicolumn{6}{|l|}{ Modeled parameters (using $\mathrm{C}(\mathrm{T})=$} \\
\hline $\mathrm{V}(\mathrm{ml} / \mathrm{kg})$ & 6378 & 6459 & 5436 & & 6091 \\
\hline \multirow[t]{2}{*}{$\mathrm{K} 10(1 / \mathrm{h})$} & 0.8424 & 0.7811 & 0.8075 & & 0.810 \\
\hline & $\begin{array}{c}\text { Rat, Sexes Combined } \\
15 \mathrm{mg} / \mathrm{kg}\end{array}$ & $45 \mathrm{mg} / \mathrm{kg}$ & $90 \mathrm{mg} / \mathrm{kg}$ & & $\operatorname{Mean}^{b}$ \\
\hline \multicolumn{6}{|l|}{ NCA parameter } \\
\hline$C_{\max }(\mathrm{ng} / \mathrm{ml})$ & 2769 & 6982 & 24,899 & & \\
\hline$C_{\max } / \mathrm{dose}(\mathrm{ng} / \mathrm{ml}) /(\mathrm{mg} / \mathrm{kg})$ & 185 & 155 & 277 & & \\
\hline $\mathrm{T}_{\max }(\mathrm{h})$ & 0.25 & 0.25 & 0.25 & & \\
\hline $\mathrm{AUC}_{\text {inf }}(\mathrm{ng} / \mathrm{h}$ per milliliter $)$ & 4199 & 14,114 & 52,563 & & \\
\hline AUC $_{\text {in }} /$ dose $(\mathrm{ng} / \mathrm{h}$ per milliliter $) /(\mathrm{mg} / \mathrm{kg})$ & 280 & 314 & 578 & & \\
\hline$t_{1 / 2}(\mathrm{~h})$ & 1.18 & 1.95 & 1.91 & & \\
\hline \multicolumn{6}{|l|}{ Modeled parameters (using $\mathrm{C}(\mathrm{T})=$} \\
\hline $\mathrm{A} \times \exp (-$ alpha $\times \mathrm{T})+\mathrm{B} \times \exp (-$ beta $\times$ & & & & & \\
\hline $\mathrm{V} 1(\mathrm{ml} / \mathrm{kg})$ & 3816 & 3862 & 1518 & & 3839 \\
\hline $\mathrm{K} 10(1 / \mathrm{h})$ & 0.87 & 0.77 & 1.09 & & 0.82 \\
\hline $\mathrm{K} 12(1 / \mathrm{h})$ & 0.61 & 1.63 & 3.49 & & 1.12 \\
\hline \multirow[t]{3}{*}{$\mathrm{K} 21(1 / \mathrm{h})$} & 1.14 & 1.68 & 2.31 & & 1.41 \\
\hline & $\begin{array}{l}\text { Cynomolgus Macaque, } \\
\text { Sexes Combined }\end{array}$ & & & & \\
\hline & $1 \mathrm{mg} / \mathrm{kg}$ & $3 \mathrm{mg} / \mathrm{kg}$ & $10 \mathrm{mg} / \mathrm{kg}$ & $30 \mathrm{mg} / \mathrm{kg}$ & Mean $^{c}$ \\
\hline \multicolumn{6}{|l|}{ NCA parameter } \\
\hline$C_{\max }(\mathrm{ng} / \mathrm{ml})$ & 161 & 539 & 1599 & 4633 & \\
\hline$C_{\text {max }} / \mathrm{dose}(\mathrm{ng} / \mathrm{ml}) /(\mathrm{mg} / \mathrm{kg})$ & 161 & 180 & 160 & 154 & \\
\hline$T_{\max }(\mathrm{h})$ & 4.0 & 3.5 & 3.75 & 5.75 & \\
\hline AUC $_{\text {inf }}$ (ng/h per milliliter) & 2287 & 5710 & 21,746 & 65,372 & \\
\hline AUC $_{\text {inf }} /$ dose $(\mathrm{ng} / \mathrm{h}$ per milliliter $) /(\mathrm{mg} / \mathrm{kg})$ & 2287 & 1903 & 2175 & 2179 & \\
\hline$t_{1 / 2}(\mathrm{~h})$ & 11.5 & 6.49 & 6.95 & 6.27 & \\
\hline \multicolumn{6}{|l|}{$\begin{array}{c}\text { Modeled parameters (using } \mathrm{C}(\mathrm{T})= \\
\mathrm{K} \times(\mathrm{D} / \mathrm{V}) \times \mathrm{T} \times \exp (-\mathrm{K} \times \mathrm{T}))\end{array}$} \\
\hline V_F $(\mathrm{ml} / \mathrm{kg})$ & 2466 & 2171 & 2324 & 2663 & 2406 \\
\hline $\mathrm{K}(1 / \mathrm{h})$ & 0.3 & 0.32 & 0.26 & 0.22 & 0.274 \\
\hline $\mathrm{T}_{\text {lag }}(\mathrm{h})^{d}$ & 0.39 & 0.45 & 0.41 & 0.52 & 0.440 \\
\hline
\end{tabular}

Amantadine PK/PD Analysis in Rats. The mean amantadine concentration-time profile for single intraperitoneal dose administration in rats is displayed in Fig. 1D. Plasma concentrations were dose proportional between 15 and $45 \mathrm{mg} / \mathrm{kg}$, which was most appropriate for the range used in the LID efficacy studies. The mean $C_{\max }$ for 15 and $45 \mathrm{mg} / \mathrm{kg}$ doses were 2769 and $6982 \mathrm{ng} / \mathrm{ml}$, respectively, and the mean $\mathrm{AUC}_{\text {inf }}$ estimates were 4199 and 14,114 $\mathrm{ng} / \mathrm{h}$ per milliliter, respectively (Table 1). A two-compartment intravenous bolus model using the full time course of available data (12 hours) was fit to the 15 and $45 \mathrm{mg} / \mathrm{kg}$ dose data (Table 1), and the average parameters were used to simulate $\mathrm{PK}$ profiles for 10 , 20, and $40 \mathrm{mg} / \mathrm{kg}$ doses (Fig. 1E).

Two previous publications, Papathanou et al. (2014) and Bortolanza et al. (2016), demonstrated a dose-dependent reduction of AIMs after a single dose of 10,20 , or $40 \mathrm{mg} / \mathrm{kg}$, i.p., amantadine in the 6-OHDA rat model with a maximum reduction of $\mathrm{AIMs}>75 \%$. In another publication, Bido et al. (2011) demonstrated that $40 \mathrm{mg} / \mathrm{kg}$, i.p., amantadine decreased AIMs, achieving a maximum reduction of $63 \%$ compared with vehicle.

The percentage reduction in AIMs was plotted as a function of the simulated amantadine plasma concentrations (Fig. 1F). A sigmoidal $\mathrm{E}_{\max }$ model provided a good fit for the data with an amantadine $\mathrm{EC}_{50}$ of $1633 \mathrm{ng} / \mathrm{ml}(95 \% \mathrm{CI}, 1419-1879 \mathrm{ng} / \mathrm{ml})$ for the reduction of AIMs (Supplemental Table 2).

Amantadine PK/PD Analysis in Cynomolgus Macaques. Dose proportionality was observed over the dose range of $1-30 \mathrm{mg} / \mathrm{kg}$ amantadine (Fig. $2 \mathrm{~A}$ ), with the mean $C_{\text {max }}$ ranging from 161 to $4633 \mathrm{ng} / \mathrm{ml}$ and the mean $\mathrm{AUC}_{\text {inf }}$ ranging from 2287 to $65,372 \mathrm{ng} / \mathrm{h}$ per milliliter (Table 1). A one-compartment model with a constrained input rate equivalent to output was fit to the data, and the average parameters (Table 1) were used to simulate PK profiles for doses of $0.3,1$, 5, 10, 20, and $30 \mathrm{mg} / \mathrm{kg}$ (Fig. 2B) that were used in the three referenced studies (Bezard et al., 2013; Grégoire et al., 2013; Ko et al., 2014). In our efficacy study, single oral doses of amantadine resulted in a dose-dependent decrease in 
A

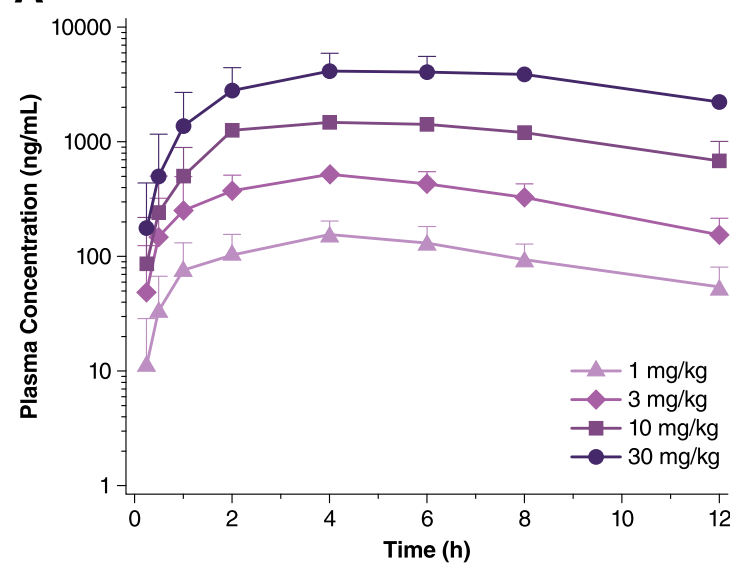

C

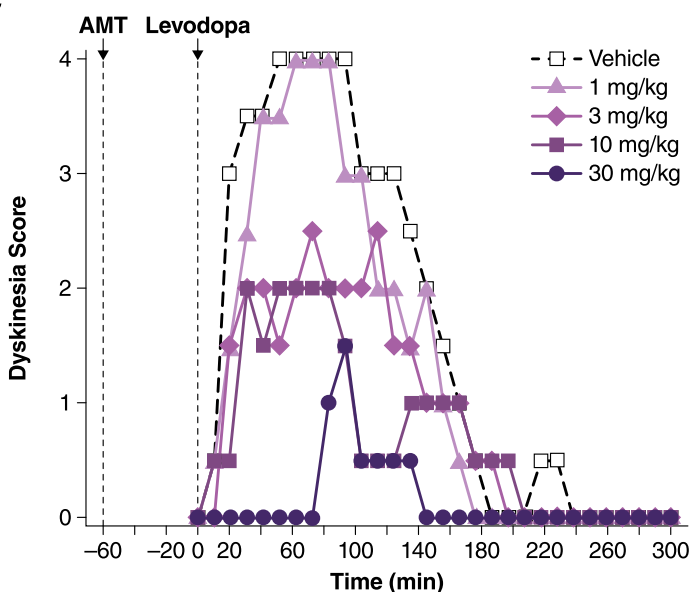

B

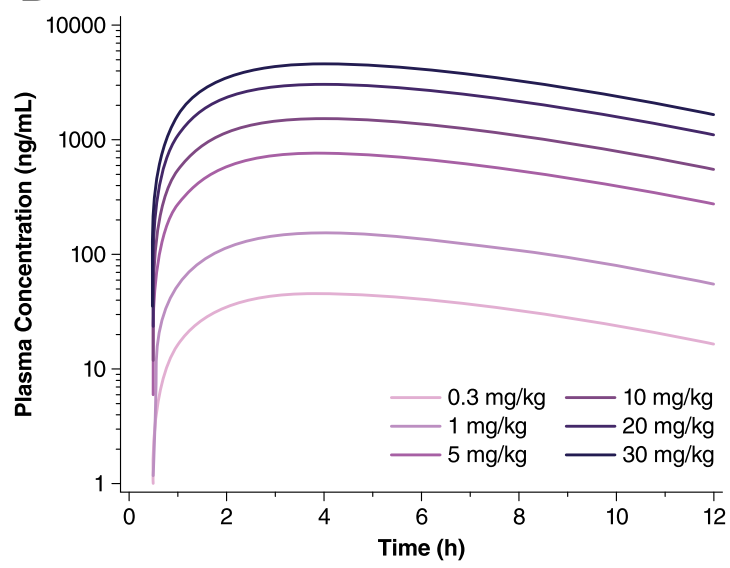

D

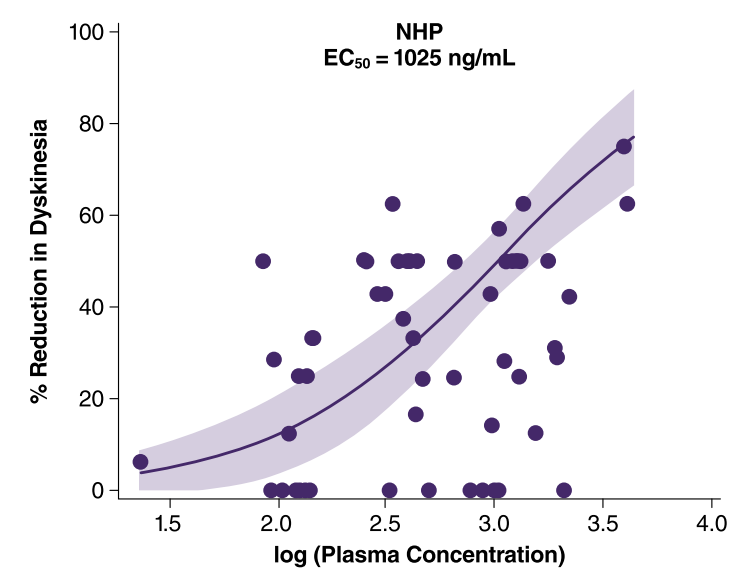

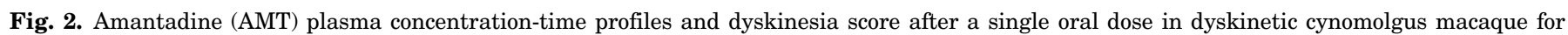

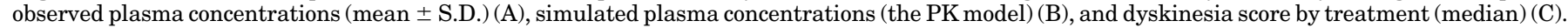

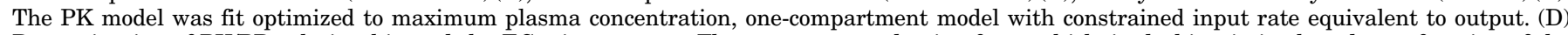

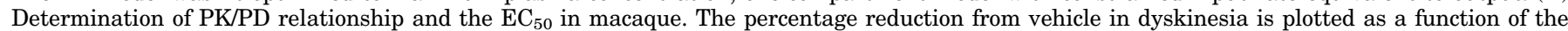
$\log$ (amantadine plasma concentration) in macaque. $\mathrm{EC}_{50}=1025 \mathrm{ng} / \mathrm{ml}$. The shaded area represents the $95 \% \mathrm{CI}$.

dyskinesia in MPTP macaques, with up to a $78 \%$ reduction in median levels of LID occurring at $30 \mathrm{mg} / \mathrm{kg}$ amantadine (Fig. 2C).

The percentage reduction in dyskinesia was plotted as a function of the simulated amantadine plasma concentrations (Fig. 2D). A sigmoidal $\mathrm{E}_{\max }$ model provided a good fit for the data with an amantadine $\mathrm{EC}_{50}$ of $1025 \mathrm{ng} / \mathrm{ml}(95 \% \mathrm{CI}$, $716-1467 \mathrm{ng} / \mathrm{ml}$ ) for the reduction of dyskinesia (Supplemental Table 2).

PK/PD Relationships Across Species. The exposureresponse relationships for mouse, rat, and macaque data each fit the sigmoidal $\mathrm{E}_{\max }$ model fairly well, with $R^{2}$ values ranging from 0.407 to 0.682 . The relationships for each species also showed close agreement with regard to the $\mathrm{EC}_{50}$, which ranged from 1025 to $1633 \mathrm{ng} / \mathrm{ml}$. Combining data from all species for model fitting resulted in estimates similar to those obtained individually, with an $R^{2}$ value of 0.429 and an $\mathrm{EC}_{50}$ value of $1367 \mathrm{ng} / \mathrm{ml}$ (95\% CI, 1139-1639 ng/ml) (Fig. 3; Supplemental Table 2).

A study was conducted in dyskinetic 6-OHDA-lesioned rats using ALZET pumps to ensure constant amantadine plasma levels that bracketed the $\mathrm{EC}_{50}(1367 \mathrm{ng} / \mathrm{ml})$. Subcutaneous infusion for 12 days of $83 \mathrm{mg} / \mathrm{kg}$ per day amantadine resulted in plasma concentrations of $2922 \mathrm{ng} / \mathrm{ml}$ (Fig. 4A), and a significant reduction from baseline in cumulative AIMs was observed at this dose compared with vehicle (37.2\% vs. $0.1 \%$ reduction, respectively; $P=0.008$ ) (Fig. 4B). Conversely, sustained plasma concentrations below $900 \mathrm{ng} / \mathrm{ml}$, achieved with infusion for 12 days of 22.5 or $45 \mathrm{mg} / \mathrm{kg}$ per day, s.c., amantadine, did not significantly impact AIMs. These data are included in the rat, and all-species $\mathrm{E}_{\max }$ models are presented in Figs. 1F and 3, respectively.

In a previously reported clinical study (Pahwa et al., 2015), steady-state amantadine plasma concentrations were measured in patients with Parkinson's disease administered 210, 274 , or $338 \mathrm{mg}$ ADS-5102 (amantadine) extended-release capsules once daily at bedtime (equivalent to 260,340 , or $420 \mathrm{mg}$ amantadine $\mathrm{HCl}$, respectively). Mean (S.D.) steadystate amantadine plasma concentrations were 1383 (354), 1431 (707), and 1677 (512) $\mathrm{ng} / \mathrm{ml}$ for the respective doses (Fig. 4C). The least-squares mean change from baseline at week 8 in the Unified Dyskinesia Rating Scale (UDysRS) total score was $-6.7,-12.3,-17.9$, and -16.7 for the placebo, 210-, 274-, and 338-mg groups, respectively (Fig. 4D). Reductions in the UDysRS total score for the 274- and 338-mg groups (corresponding to $43 \%$ and $41 \%$ reduction, respectively) were significant compared with placebo, and are consistent with the nonclinical PK/PD relationship described above. 


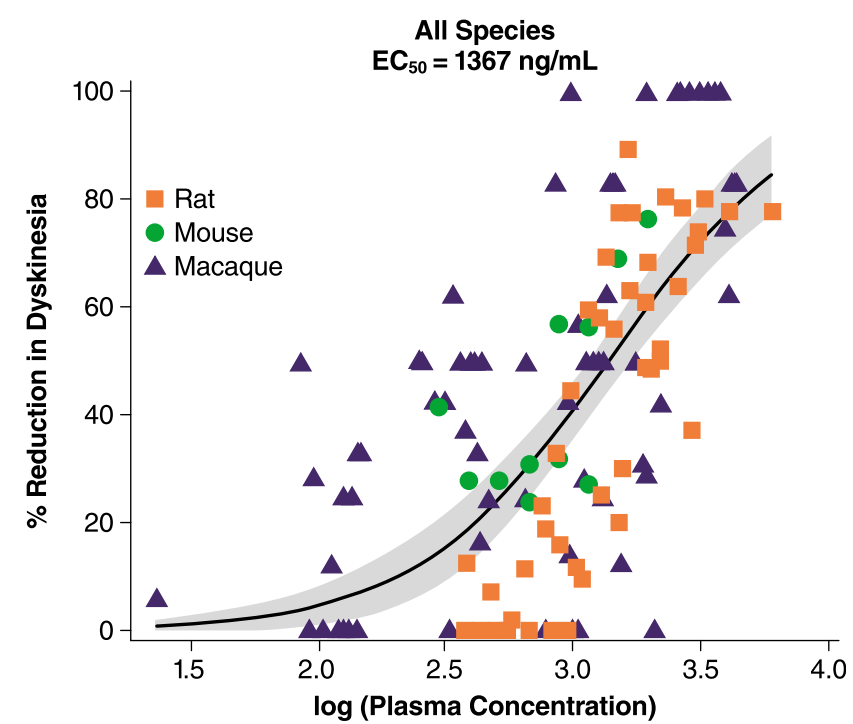

Fig. 3. Determination of the $\mathrm{PK} / \mathrm{PD}$ relationship and the $\mathrm{EC}_{50}$ values across species. The percentage reduction from vehicle in AIMs (mouse and rat) or dyskinesia (macaque) is plotted as a function of the log(amantadine plasma concentration) in mouse, rat, and macaque. $\mathrm{EC}_{50}=1367 \mathrm{ng} / \mathrm{ml}$. The shaded area represents the $95 \%$ CI.

\section{Discussion}

Amantadine has been shown to be effective in reducing dyskinesia in animal models of LID as well as in patients with Parkinson's disease treated with levodopa, but the plasma concentrations associated with efficacy have not been well characterized. The analyses described herein are the first to correlate amantadine plasma concentrations with efficacy endpoints for reducing dyskinesia in different species and models of LID. Using an approach that correlates simulated amantadine plasma concentrations from mouse, rat, and macaque PK studies with the previously published and new efficacy data for reducing dyskinesia in LID models, these results define exposure-response relationships that fit sigmoidal $\mathrm{E}_{\max }$ models and predict $\mathrm{EC}_{50}$ values between 1025 and $1633 \mathrm{ng} / \mathrm{ml}$ when assessed individually or combining data from all species. Differences in plasma protein binding, bloodbrain partitioning, NMDA receptor affinity, or models of Parkinson's disease might have been anticipated to affect the efficacy of amantadine in reducing LID across the species. However, these results show that without correcting for any differences, an $\mathrm{EC}_{50}$ of approximately $1400 \mathrm{ng} / \mathrm{ml}$ appears to be a commonality across the species examined and provides a target therapeutic plasma amantadine concentration for reducing dyskinesia in patients with Parkinson's disease.

Further support for the efficacy of this range of concentrations is provided by the study in the rat 6-OHDA model dosed with a constant subcutaneous infusion of amantadine, which showed significant percentage reductions from baseline in cumulative AIM assessments compared with vehicle for average plasma concentrations of $2922 \mathrm{ng} / \mathrm{ml}$, whereas no significant effect on AIMs was observed in the dose groups resulting in average amantadine plasma concentrations below $900 \mathrm{ng} / \mathrm{ml}$. Additionally, clinical data from patients with Parkinson's disease treated with the recommended dose of $274 \mathrm{mg}$ ADS-5102 showed a statistically significant reduction in dyskinesia and a mean steady-state amantadine plasma concentration of $\sim 1500 \mathrm{ng} / \mathrm{ml}$, which approximates the $\mathrm{EC}_{50}$ value described for the nonclinical species (Pahwa et al., 2015). In the study by Pahwa et al. (2015), the median amantadine plasma concentration in patients who discontinued due to CNS-related AEs was approximately $2100 \mathrm{ng} / \mathrm{ml}$. Verhagen Metman et al. (1998b) reported that amantadine IR reduced dyskinesia in patients with Parkinson's disease treated with levodopa, with plasma concentrations that were consistent with the PK/PD model presented herein (average plasma concentration, $\sim 1600 \mathrm{ng} / \mathrm{ml}$ ), despite differences in study design elements and endpoint measures. Although limited, the PK/PD data in patients with Parkinson's disease provide support that the animal models are predictive of a relationship between amantadine plasma concentration and reduction in dyskinesia in humans.

Improvements in continuous delivery of amantadine would provide a smooth PK profile achieving high concentrations and better coverage throughout the day compared with the peaks and troughs associated with bolus dosing. As reported in the study by Hauser et al. (2018), ADS-5102 can be dosed once daily at bedtime to achieve high morning and sustained daytime amantadine plasma concentrations when symptoms of dyskinesia occur. PK modeling suggested the recommended daily ADS5102 dosage ( $274 \mathrm{mg}$ once daily at bedtime) provided maximum steady-state concentrations of $\sim 1500 \mathrm{ng} / \mathrm{ml}$ in patients with Parkinson's disease, which is approximately 2 -fold higher than that achieved with amantadine IR dosing $(81 \mathrm{mg}$, equivalent to amantadine $\mathrm{HCl} 100 \mathrm{mg}$, administered at 8:00 AM and 4:00 PM, based on prescription data, which indicated that $~ 85 \%$ of patients with Parkinson's disease treated with amantadine IR were prescribed a dose of $\leq 161 \mathrm{mg} /$ day) (Navarro et al., 2017). Therefore, target amantadine plasma concentrations required to reduce dyskinesia based on the current model can be achieved throughout the day with the recommended once-daily dose of ADS-5102 but not with the commonly used dosing paradigm for amantadine IR.

Collectively, these data show good correlation across species between amantadine plasma concentrations and reduction in LID, highlighting an $\mathrm{EC}_{50}$ value of approximately $1400 \mathrm{ng} / \mathrm{ml}$ $(\sim 9 \mu \mathrm{M})$ as an efficacious target plasma concentration. Although the mechanism of amantadine for the reduction in dyskinesia and OFF remains to be fully elucidated, these results also correlate well with the range of 50\% inhibitory drug concentration values $\left(\mathrm{IC}_{50}\right)$ reported for amantadine for the NMDA receptor (10-90 $\mu \mathrm{M}$ ) (Kornhuber et al., 1991; Bresink et al., 1995; Parsons et al., 1995, 1996). In particular, the $\mathrm{IC}_{50}$ of amantadine for the inhibition of striatal NMDA receptors was reported to be $12 \mu \mathrm{M}$ (Parsons et al., 1996), or $1800 \mathrm{ng} / \mathrm{ml}$, and support the involvement of the NMDA receptor and the glutamatergic pathway in mediating the expression of dyskinesia and motor complications in Parkinson's disease.

In summary, the correlation between the effective concentrations in animals (rodents and NHPs, $\sim 1400 \mathrm{ng} / \mathrm{ml}$ ) and efficacious plasma concentrations in humans $(1500 \mathrm{ng} / \mathrm{ml})$ demonstrates that animal models of LID are predictive of efficacy in humans. Theseresults provide a benchmark amantadine plasma concentration of $\sim 1400 \mathrm{ng} / \mathrm{ml}$ for the reduction of dyskinesia, and provide evidence that the recommended dose of ADS-5102 $(274 \mathrm{mg})$ can provide plasma concentrations in patients with Parkinson's disease that achieve that benchmark, further supporting the use of ADS-5102 for the treatment of dyskinesia in patients with Parkinson's disease. 

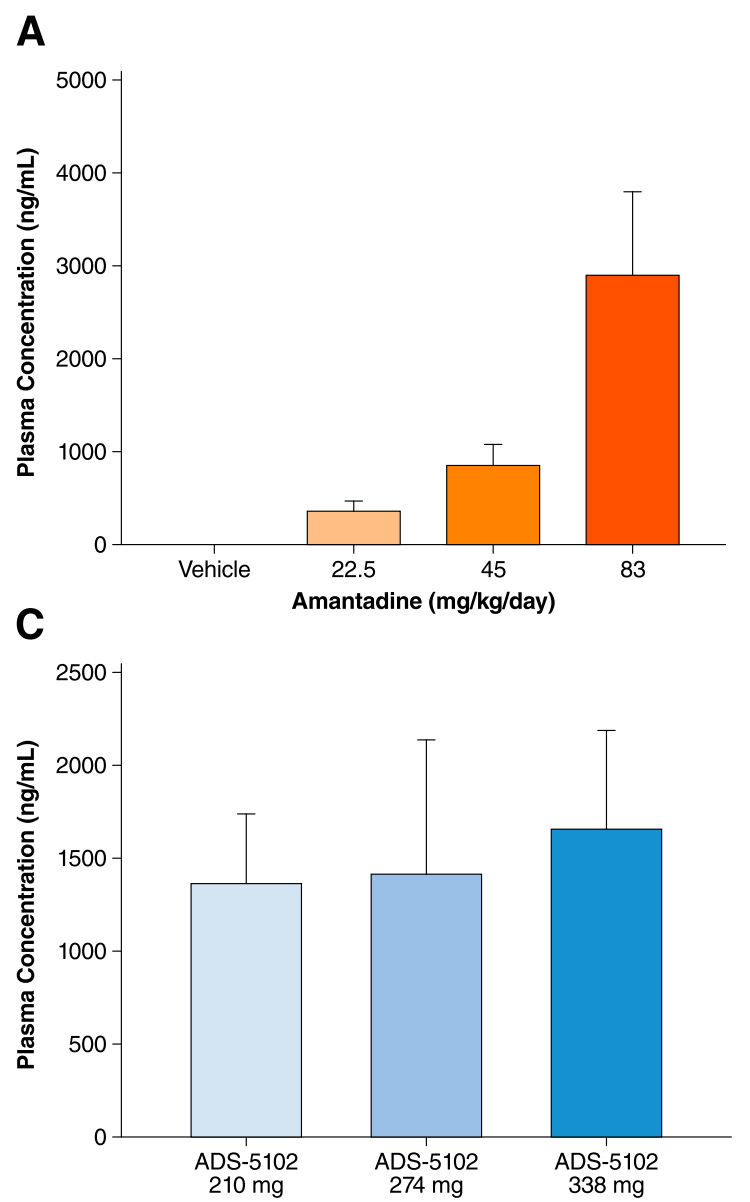

B

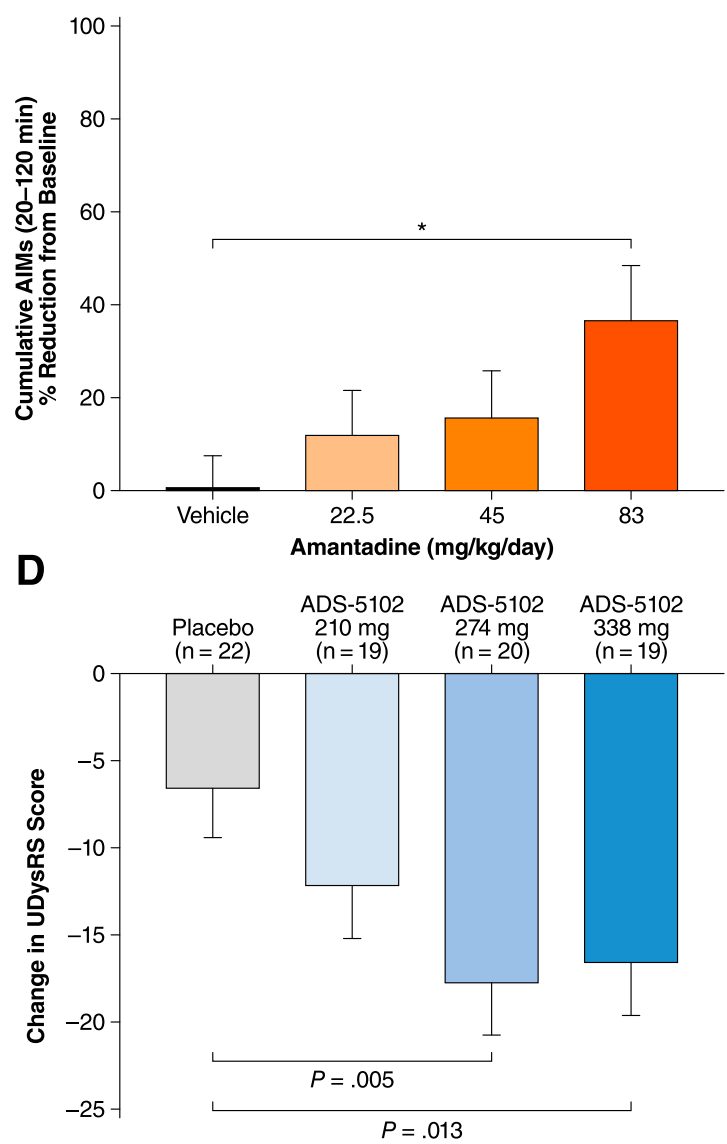

Fig. 4. Comparison of amantadine plasma concentrations (mean \pm S.D.) (A) and associated cumulative AIMs (percentage reduction from baseline, mean \pm S.E.M.) (B) in a rat 6-OHDA levodopa-induced dyskinesia model dosed with a constant subcutaneous infusion of amantadine for 12 days. The percentage reduction of AIMs was statistically significant $(P=0.008)$ for the $83 \mathrm{mg} / \mathrm{kg}$ per day amantadine dose, designated by the asterisk. Mean $( \pm \mathrm{S}$. D.) steady-state amantadine plasma concentrations (C) and observed change in UDysRS total score (least-squares mean \pm S.E.) (D) from baseline to week 8 (a decrease indicates improvement). Doses are represented as freebase. These plasma concentrations are predicted to represent high, sustained amantadine exposure throughout the waking hours based on steady-state PK in healthy subjects (Hauser et al., 2018). Source: Pahwa et al. (2015): reprinted with permission.

\section{Acknowledgments}

We thank The Curry Rockefeller Group, LLC, and Nuventra Pharma Sciences for editorial support, which was funded by Adamas Pharmaceuticals, Inc.

\section{Authorship Contributions}

Participated in research design: Brigham, Johnston, Holt, and Nguyen.

Conducted experiments: Brigham, Johnston, Brown, Fox, and Brotchie.

Performed data analysis: Brigham, Johnston, and Brown.

Wrote or contributed to the writing of the manuscript: Brigham, Johnston, Brown, Holt, Fox, Hill, Howson, Brotchie, and Nguyen.

\section{References}

Ahlskog JE and Muenter MD (2001) Frequency of levodopa-related dyskinesias and motor fluctuations as estimated from the cumulative literature. Mov Disord 16 $448-458$.

Bezard E, Tronci E, Pioli EY, Li Q, Porras G, Björklund A, and Carta M (2013) Study of the antidyskinetic effect of eltoprazine in animal models of levodopa-induced dyskinesia. Mov Disord 28:1088-1096.

Bibbiani F, Oh JD, Kielaite A, Collins MA, Smith C, and Chase TN (2005) Combined blockade of AMPA and NMDA glutamate receptors reduces levodopa-induced motor complications in animal models of PD. Exp Neurol 196:422-429.

Bido S, Marti M, and Morari M (2011) Amantadine attenuates levodopa-induced dyskinesia in mice and rats preventing the accompanying rise in nigral GABA levels. J Neurochem 118:1043-1055.

Blanchet PJ, Konitsiotis S, and Chase TN (1998) Amantadine reduces levodopainduced dyskinesias in parkinsonian monkeys. Mov Disord 13:798-802.
Bortolanza M, Bariotto-Dos-Santos KD, Dos-Santos-Pereira M, da-Silva CA, and Del-Bel E (2016) Antidyskinetic effect of 7-nitroindazole and sodium nitroprusside associated with amantadine in a rat model of Parkinson's disease. Neurotox Res 30:88-100.

Bresink I, Danysz W, Parsons CG, and Mutschler E (1995) Different binding affinities of NMDA receptor channel blockers in various brain regions-indication of NMDA receptor heterogeneity. Neuropharmacology 34:533-540.

Calon F, Morissette M, Ghribi O, Goulet M, Grondin R, Blanchet PJ, Bédard PJ, and Di Paolo T (2002) Alteration of glutamate receptors in the striatum of dyskinetic 1-methyl-4-phenyl-1,2,3,6-tetrahydropyridine-treated monkeys following dopamine agonist treatment. Prog Neuropsychopharmacol Biol Psychiatry 26:127-138.

Dekundy A, Lundblad M, Danysz W, and Cenci MA (2007) Modulation of L-DOPAinduced abnormal involuntary movements by clinically tested compounds: further validation of the rat dyskinesia model. Behav Brain Res 179:76-89.

Dupre KB, Ostock CY, Eskow Jaunarajs KL, Button T, Savage LM, Wolf W, and Bishop C (2011) Local modulation of striatal glutamate efflux by serotonin $1 \mathrm{~A}$ receptor stimulation in dyskinetic, hemiparkinsonian rats. Exp Neurol 229:288-299.

Grégoire L, Jourdain VA, Townsend M, Roach A, and Di Paolo T (2013) Safinamide reduces dyskinesias and prolongs L-DOPA antiparkinsonian effect in parkinsonian monkeys. Parkinsonism Relat Disord 19:508-514.

Hayden FG, Hoffman HE, and Spyker DA (1983) Differences in side effects of amantadine hydrochloride and rimantadine hydrochloride relate to differences in pharmacokinetics. Antimicrob Agents Chemother 23:458-464.

Hauser RA, Pahwa R, Wargin WA, Souza-Prien CJ, McClure N, Johnson R, Nguyen JT, Patni R, and Went GT (2018) Pharmacokinetics of ADS-5102 (amantadine) extended release capsules administered once daily at bedtime for the treatment of dyskinesia. Clin Pharmacokinet DOI:10.1007/s40262-018-0663-4.

Hill MP, Ravenscroft P, Bezard E, Crossman AR, Brotchie JM, Michel A, Grimée R, and Klitgaard $\mathrm{H}$ (2004) Levetiracetam potentiates the antidyskinetic action of amantadine in the 1-methyl-4-phenyl-1,2,3,6-tetrahydropyridine (MPTP)-lesioned primate model of Parkinson's disease. J Pharmacol Exp Ther 310:386-394.

Jonkers N, Sarre S, Ebinger G, and Michotte Y (2002) MK801 suppresses the L-DOPA-induced increase of glutamate in striatum of hemi-Parkinson rats. Brain Res 926:149-155. 
Ko WK, Pioli E, Li Q, McGuire S, Dufour A, Sherer TB, Bezard E, and Facheris MF (2014) Combined fenobam and amantadine treatment promotes robust antidyskinetic effects in the 1-methyl-4-phenyl-1,2,3,6-tetrahydropyridine (MPTP) lesioned primate model of Parkinson's disease. Mov Disord 29:772-779.

Kobylecki C, Hill MP, Crossman AR, and Ravenscroft P (2011) Synergistic antidyskinetic effects of topiramate and amantadine in animal models of Parkinson's disease. Mov Disord 26:2354-2363.

Kornhuber J, Bormann J, Hübers M, Rusche K, and Riederer P (1991) Effects of the 1-amino-adamantanes at the MK-801-binding site of the NMDA-receptor-gated ion channel: a human postmortem brain study. Eur J Pharmacol 206:297-300.

Navarro R, Whangbo A, Pahwa R, Isaacson SH, Schmidt P, and Went GT (2017) An assessment of the persistence and medication possession ratio of adjunctive treatments to levodopa in patients with Parkinson's disease (PD), in ISPOR 2017: The International Society for Pharmacoeconomics and Outcomes Research 22nd Annual International Meeting; 2017 May 20-24; Boston, MA.

Oertel W, Eggert K, Pahwa R, Tanner CM, Hauser RA, Trenkwalder C, Ehret R, Azulay JP, Isaacson S, Felt L, et al. (2017) Randomized, placebo-controlled trial of ADS-5102 (amantadine) extended-release capsules for levodopa-induced dyskinesia in Parkinson's disease (EASE LID 3). Mov Disord 32:1701-1709.

Pahwa R, Tanner CM, Hauser RA, Isaacson SH, Nausieda PA, Truong DD, Agarwal P, Hull KL, Lyons KE, Johnson R, et al. (2017) ADS-5102 (amantadine) extendedrelease capsules for levodopa-induced dyskinesia in Parkinson disease (EASE LID study): a randomized clinical trial. JAMA Neurol 74:941-949.

Pahwa R, Tanner CM, Hauser RA, Sethi K, Isaacson S, Truong D, Struck L, Ruby AE, McClure NL, Went GT, et al. (2015) Amantadine extended release for levodopa-induced dyskinesia in Parkinson's disease (EASED study). Mov Disord 30:788-795.

Papa SM and Chase TN (1996) Levodopa-induced dyskinesias improved by a glutamate antagonist in Parkinsonian monkeys. Ann Neurol 39:574-578.

Papathanou M, Jenner P, Iravani M, Jackson M, Stockwell K, Strang I, Zeng BY, McCreary AC, and Rose S (2014) The H3 receptor agonist immepip does not affect l-dopa-induced abnormal involuntary movements in 6-OHDA-lesioned rats. Eur $J$ Pharmacol 741:304-310.

Paquette MA, Martinez AA, Macheda T, Meshul CK, Johnson SW, Berger SP, and Giuffrida A (2012) Anti-dyskinetic mechanisms of amantadine and dextromethorphan in the 6-OHDA rat model of Parkinson's disease: role of NMDA vs. 5-HT1A receptors. Eur J Neurosci 36:3224-3234.
Parkes JD, Zilkha KJ, Marsden P, Baxter RC, and Knill-Jones RP (1970) Amantadine dosage in treatment of Parkinson's disease. Lancet 1:1130-1133.

Parsons CG, Panchenko VA, Pinchenko VO, Tsyndrenko AY, and Krishtal OA (1996) Comparative patch-clamp studies with freshly dissociated rat hippocampal and striatal neurons on the NMDA receptor antagonistic effects of amantadine and memantine. Eur $J$ Neurosci 8:446-454.

Parsons CG, Quack G, Bresink I, Baran L, Przegalinski E, Kostowski W, Krzascik P, Hartmann S, and Danysz W (1995) Comparison of the potency, kinetics and voltage-dependency of a series of uncompetitive NMDA receptor antagonists in vitro with anticonvulsive and motor impairment activity in vivo. Neurophar macology 34:1239-1258.

Paxinos G and Watson C (1986) The Rat Brain in Stereotaxic Coordinates, 2nd ed, Academic Press, Orlando, FL.

Robelet S, Melon C, Guillet B, Salin P, and Kerkerian-Le Goff L (2004) Chronic L-DOPA treatment increases extracellular glutamate levels and GLT1 expression in the basal ganglia in a rat model of Parkinson's disease. Eur $J$ Neurosci 20 $1255-1266$

Sebastianutto I, Maslava N, Hopkins CR, and Cenci MA (2016) Validation of an improved scale for rating l-DOPA-induced dyskinesia in the mouse and effects of specific dopamine receptor antagonists. Neurobiol Dis 96:156-170.

Sgambato-Faure V and Cenci MA (2012) Glutamatergic mechanisms in the dyskinesias induced by pharmacological dopamine replacement and deep brain stimulation for the treatment of Parkinson's disease. Prog Neurobiol 96:69-86.

Suh DC, Pahwa R, and Mallya U (2012) Treatment patterns and associated costs with Parkinson's disease levodopa induced dyskinesia. J Neurol Sci 319:24-31.

Verhagen Metman L, Blanchet PJ, van den Munckhof P, Del Dotto P, Natté R, and Chase TN (1998a) A trial of dextromethorphan in parkinsonian patients with motor response complications. Mov Disord 13:414-417.

Verhagen Metman L, Del Dotto P, van den Munckhof P, Fang J, Mouradian MM, and Chase TN (1998b) Amantadine as treatment for dyskinesias and motor fluctuations in Parkinson's disease. Neurology 50:1323-1326.

Address correspondence to: Jack T. Nguyen, Adamas Pharmaceuticals, Inc., 1900 Powell Street, Suite 750, Emeryville, CA 94608. E-mail: jnguyen@ adamaspharma.com 